\title{
Non-thermal Plasma System for Marine Diesel Engine Emission Control
}

\author{
${ }^{1}$ Wamadeva Balachandran, Fellow, IEEE, ${ }^{1}$ Nadarajah Manivannan, SM IEEE, ${ }^{1}$ Radu \\ Beleca, Member IEEE, ${ }^{1}$ Maysam Abbod, ${ }^{1}$ David Brennen, ${ }^{2}$ Nehemiah Sabinus Alozie and \\ ${ }^{2}$ Lionel C. Ganippa \\ ${ }^{1}$ Centre for Electronic Systems Research \\ ${ }^{2}$ Centre for Advanced Powertrain and Fuels Research \\ College of Engineering, Design and Physical Sciences \\ Brunel University London \\ Kingston Lane, Uxbridge, UB8 3PH, UK \\ Wamadeva.Balachandran@brunel.ac.uk
}

\begin{abstract}
A non-thermal plasma reactor (NTPR) using two 2.45 GHz Microwave (MW) generators for the abatement of Nitrogen Oxides (NOx) and Sulphur (SOx) contained in the exhaust gas of a $200 \mathrm{~kW}$ marine diesel engine was built and tested. Numerical analysis based on a non-thermal plasma kinetics model for the abatement of NOx and SOx from marine diesel engine exhaust gas was performed. A generic kinetic model that implements electron collisions and plasma chemistry has been developed for applications involving low temperature $(50 \mathrm{~K}-100 \mathrm{~K})$ non-thermal plasma. Abatement efficiencies of NOx and SOx were investigated for a range of mean electron energies which directly impact on the rate constants of electron collisions. The simulation was conducted using the expected composition of exhaust gas from a typical two-stroke slow speed marine diesel engine. The simulation results predict that mean electron energy of $0.25 \mathrm{eV}-3.2 \mathrm{eV}$ gives abatement efficiency of 99\% for NOx and SOx. The minimum residence time required was found to be $80 \mathrm{~ns}$ for the mean electron energy was $1 \mathrm{eV}$.

Multi-mode cavity was designed using COMSOL multi-physics. The NTPR performance in terms of NOx and SOx removal was experimentally tested using the exhaust from a $2 \mathrm{~kW}$ lab scale two stroke diesel engine. The experimental results also show that complete removal of $\mathrm{NO}$ is possible with the microwave plasma (yellow in color) generated. However it was found that generating right Microwave plasma is a challenging task and requires further investigation.
\end{abstract}

Index Terms - NOx Abatement, Marine Diesel Engine Exhaust, Microwave Plasma, Non-Thermal Plasma, Numerical Modelling.

\section{INTRODUCTION}

International shipping traffic presents itself today as a major challenge in terms of impact on environment and human health which entails substantive economic consequences [1$3]$. The two and four-stroke diesel engines fueled with relatively "inexpensive" heavy-fuel oils (HFO) are the dominant power plants for ship propulsions. The benefits of abundant and low cost HFO is currently being challenged by regulations of the substantial air pollutants emitted at the exhausts. The primary air pollutants emitted by marine diesel engines are SOx, NOx, and Particulate Matter (PM) which encompasses the volatile organic compounds (VOC) and Black Carbon (BC) or soot [4].
The impact of air pollutants generated by ship engines both in gaseous and particulate forms, is of concern to the atmospheric environment as it can cause significant exposure to risk for people living within proximities of harbors or in neighboring coastal areas [5]. It was recently estimated, that ships produce at least $15 \%$ of the world's NOx (more than all of the world's cars, buses and trucks combined), between 2.5 - $4 \%$ of greenhouse gases, 5\% black carbon (BC), and between $3-7 \%$ of global $\mathrm{SO}_{2}$ output [6]. An estimate of the contributions to the global emissions of VOC and $\mathrm{CO}$ is not yet available. In order to reduce the environmental footprint of ships, the International Maritime Organization (IMO) recently issued the legislation of Marpol Annex VI guidelines which implies especially the introduction of, inter alia, stricter sulphur limits for marine fuel in Emission Control Zones (ECAs) under the revised MARPOL Annex VI, to $3.50 \%$ (from the current $4.50 \%$ ), effective from 1 January 2012; then progressively to $0.50 \%$, effective from 1 January 2020, subject to a feasibility review to be completed no later than 2018[7] The limits applicable in ECAs for SOx and particulate matter were reduced to $1.00 \%$, beginning on 1 July 2010 (from the original $1.50 \%$ ); being further reduced to $0.10 \%$, effective from 1 January 2015. The Tier III controls apply only to the specified ships built from 2016 while operating in ECA established to limit NOx emissions; outside such areas the Tier II controls apply [7]. The United States and Canada adopted national regulations enforcing IMO Tier III equivalent limits within the North American ECA effective 2016. However the US Environmental Protection Agency (EPA) rule for Category III ships, takes reference from the international IMO standards. If the IMO emission standards are delayed, the Tier III standards would be applicable from 2016 only for US flagged vessels. One of the proposed solutions towards marine diesel emission control is the non-thermal plasma process $[8,9]$.

\section{A. Economic Impact}

Considering the above pollutants Economic Valuation of Air Pollution model (EVA) predicts that due to a general increase in the ship traffic worldwide the total external pollution costs in Europe will increase to 64.1 billion Euros 
$(€) / y e a r$ in the year 2020 from 58.4 billion $€ /$ year costs in the year 2000 [10]. If we examine the relative external costs from all international ship traffic, it was responsible for an estimated $7 \%$ of the total health effects in Europe air pollution in the year 2000 and will increase to $12 \%$ in the year 2020[11].

\section{B. Legislation}

As from March 2014, the ECAs established limit for SOx and PM emissions in Baltic Sea area as defined in Annex I of MARPOL; in North Sea area (including the English Channel) as defined in Annex V of MARPOL; North American area (entered into force on 1st August 2012); and United States Caribbean Sea (entered into force on 1st January 2014) [7]. However, regulatory frameworks and industrial benchmarks do not include Carbon monoxide ( $\mathrm{CO}$ ), polycyclic-aromatic hydrocarbons (PAHs), persistent organic pollutants (POPs), metals, heavy metals, dioxins, and secondary organic aerosols (SOA) or related external costs on the natural environment or climate. CO, hydrocarbons (HC) and PM are considered priority for EU and the US environmental agencies. In 2012, diesel particulate was classified as carcinogenic to humans by the World Health Organization (WHO) [12]. Since 2011, IMO instituted a commission to address measures to contain $\mathrm{BC}$ emission from ships, since $\mathrm{BC}$ is considered the second most important climate forcing agent with warming effect; its removal contributes to an equivalent reduction of greenhouse gases, together with $\mathrm{CO}_{2}$ [2]. To comply with the existing and the future IMO regulations, all existing and future ships must adopt measures to reduce their specific emissions (gram of pollutant emitted for each $\mathrm{kWh}$ ). This means that while new ships will be properly designed to reduce such emissions, existing ships must be retrofitted.

\section{Retrofit versus Fuel Switching}

To be more effective, ships have to become more environmentally friendly and more energy efficient. Energy efficiency can be achieved by reducing the specific energy demand of ships, through new concepts of engine design, naval architecture and routing. Energy efficiency is also achieved by assuring the best use of the worldwide energy mix. In this sense, also the intermediate fuel oil (IFO) commonly used by ships as cost effective fuels has a limited market and its conversion into diesel is expensive and ineffective. To date, maritime traffic within EU ports requires use of costly low sulphur fuels, which will significantly impact on the shipping industry. Experts believe ship owners will opt for marine gasoil (MGO) by 2015 or alternative fuels such as Liquefied Natural Gas (LNG). LNG is still limited in use because of high investment costs and lack of adequate infrastructure. In this scenario there are many favorable predictions towards marine scrubbers to become the 'dominant technology' in cutting marine fuel emissions with continued use of IFO.

\section{Retrofitting Technologies}

Currently there are 300 scrubbers being commissioned in EU within the ECA for various engine sizes with a total manufacturing value of $£ 4$ million/unit [13]. It is estimated that by 2020 a total of 80000 ships would require retrofitting worldwide in order to meet emissions regulations [7]. The state-of-the-art conventional technologies for flue gas treatment aimed at SOx and NOx emission control are wet, dry and semi-dry flue gas desulphurization (FGD) and selective catalytic reduction (SCR). To date, ship retrofitting to meet atmospheric emission control is focused on $\mathrm{SO}_{2}, \mathrm{NOx}$ and coarse PM $(>1 \mu \mathrm{m})$ removal. Scrubbers can be suitably adopted to remove $\mathrm{SO}_{2}$ and $\mathrm{PM}$, while Selective Catalytic Reduction reactors (SCR) are required for the removal of NOx. Scrubbers and SCR systems (e.g. MAN diesel SCR system $\approx 85 \%$ NOx reduction) are expensive and the retrofit operation quite complex due to the high footprint and volume of the equipment. The overall capital cost of a scrubber system is largely related to the system auxiliaries. Operational costs of scrubbers are mainly related to the water needs, (an average of about $48 \mathrm{~T} / \mathrm{MWh}$ ), the amount of which leads to complex and expensive waste water treatments. SCR systems have high operating cost related to the periodic replacement of catalysts and urea or ammonia for NOx conversion before the gas stream reaches the catalyst. These substances need to be stored on ships in significant volumes for continuous operation of the SCR unit.

Recently Wärtsilä proposed a new open loop scrubber system while its hybrid scrubber has the flexibility to operate in both open and closed loop [14]. These systems performance limits to $\mathrm{SOx}$ removal $\approx 97 \%$ and $\mathrm{PM} \approx 85 \%$ and require significant levels of water, several types of collection tanks (e.g. sludge tank, holding tank) and caustic soda as reagent (for scrubbers using fresh water). Clean Marine offers a similar solution in form of a hybrid system which aims at reducing PM by developing a wet scrubber technology with high speed cyclone based on the Advanced Vortex Chamber (AVC) principle [7].

\section{E. Non-thermal Plasma}

Non-thermal plasma as dry or wet system is an emerging technology for VOC, SOx and NOx emission control with low power consumption and by-product production $[15,16]$. The fundamental nature of non-thermal plasma is that the electron temperature is much higher than that of the gas temperature, including molecular vibrational and rotational temperatures. High energetic electrons induce molecular excitation, ionization and dissociation, and at the same time involve the attachment of lower energy electrons that form negative ions in the discharge area. Secondary plasma reactions will be initiated by dissociated molecules, radicals and ions by radical-molecule reactions and ion-molecule reactions in the downstream afterglow discharge region. Solutions combined with other processes (such as adsorption 
or wet-type chemical scrubbing) have been proposed, some are already at pilot scale test [17].

Electron beam (EB) flue gas treatment technology is among the most promising advanced technologies of the new generation [18, 19]. This is a dry-scrubbing process for simultaneous $\mathrm{SO}_{2}$ and $\mathrm{NOx}$ removal where no waste except the by-product is generated. The energy of the incident electron beam is absorbed by components of stack gas in proportion to their mass fraction. The main components of stack gas are $\mathrm{N}_{2}, \mathrm{O}_{2}, \mathrm{H}_{2} \mathrm{O}$ and $\mathrm{CO}_{2}$, with much lower concentration of $\mathrm{SO}_{2}$ and $\mathrm{NOx}$. Electron energy is consumed in the ionization, excitation and dissociation of the molecules and finally in the formation of active free radicals $\mathrm{OH}, \mathrm{HO}_{2}{ }^{\circ}$ $\mathrm{O}^{*}, \mathrm{~N}^{*}$ and $\mathrm{H}^{*}$. These radicals oxidize $\mathrm{SO}_{2}$ and $\mathrm{NO}$ to $\mathrm{SO}_{3}$ and $\mathrm{NO}_{2}$ which, in turn reacts with water vapor present in the stack gas, to form $\mathrm{H}_{2} \mathrm{SO}_{4}$ and $\mathrm{HNO}_{3}$ respectively, and also break VOC bonds thereby promoting their conversion to $\mathrm{CO}$ and $\mathrm{CO}_{2}$.

Microwave (MW) irradiation is a viable and promising method for flue gas cleaning in view of the reduction of power consumption of the gas treatment process [20-22]. The absence of internal electrodes removes a source of contamination and makes the reaction chamber simpler for microwave induced non-thermal plasma. MW irradiation produces much higher degree of ionization and dissociation that commonly gives 10 times higher yield of active species than other types of electrically excited plasma.

Brunel University as part of the DEECON FP7 EU project has designed and built a non-thermal plasma reactor (NTPR) using two microwave generators which is aimed at treating exhaust gases from a $200 \mathrm{~kW}$ two stroke marine engine [20, 23]. The main goals of the NTPR will be the abatement of submicron particulate matter (removal efficiency of $90 \%$ and the removal of harmful gases, with particular attention to nitric oxide and nitrogen dioxide (removal efficiency 98\%). The NTPR module was further integrated with an Electrostatic Sea Water Scrubber (ESWS) developed by our project partners coupled together with other components aim at providing complete sustainable solution for marine diesel exhaust abatement [24, 25]. In this paper, some of the key results obtained from the computer simulation of plasma kinetics and experimental results obtained for the reduction of NOx are presented.

\section{NON-THERMAL PlaSMA KINETICS AND NUMERICAL MODELING}

The basic principle of non-thermal plasma is such that electron temperature (Te) and gas temperature $(\mathrm{Tg})$ greatly differ in magnitude such that $\mathrm{Te} \gg \mathrm{Tg}$ [26]. High energy electrons collide with gas molecules and the impact produces various radicals and ions. In the case of exhaust stream from marine diesel engine which contains high concentrations of $\mathrm{CO}_{2}, \mathrm{H}_{2} \mathrm{O}, \mathrm{N}_{2}$ and low concentrations of $\mathrm{NOx}$, and $\mathrm{SO}_{2}, \mathrm{PM}$, the major radicals produced are $\mathrm{OH} \cdot, \mathrm{O} \cdot \mathrm{N} \cdot \mathrm{N}$ and $\mathrm{H} \cdot$. When these radicals interact with $\mathrm{NOx}$ and $\mathrm{SOx}$, they form weak $\mathrm{H}_{2} \mathrm{SO}_{4}$ and $\mathrm{HNO}_{3}$ respectively. These weak acids can be further treated or infinitely diluted before disposal into sea after appropriate adjustment of the $\mathrm{pH}$ levels commensurate to regulatory standards [27]. 
Table 1: Plasma chemistry and associated reactions rate constants of the conversion of $\mathrm{NOx}$ and $\mathrm{SO}_{2}$ into $\mathrm{H}_{2} \mathrm{SO}_{4}$ and $\mathrm{HNO}_{3}$. T - Temperature of gas.

\begin{tabular}{|c|c|c|c|}
\hline Reactions & \multicolumn{2}{|r|}{ Reaction Rate [28-30] } & Index \\
\hline $\mathrm{e}+\mathrm{H}_{2} \mathrm{O} \rightarrow \mathrm{OH}^{-}+\mathrm{H}^{-}+\mathrm{e}$ & $\mathrm{k}_{\mathrm{d} 1}$ & \multirow{3}{*}{ See Figure 1} & (R1) \\
\hline $\mathrm{e}+\mathrm{O}_{2} \rightarrow \mathrm{O}^{\circ}+\mathrm{O}^{\circ}+\mathrm{e}$ & $\mathrm{k}_{\mathrm{d} 2}$ & & (R2) \\
\hline $\mathrm{e}+\mathrm{N}_{2} \rightarrow \mathrm{N}^{\prime}+\mathrm{N}^{\cdot}+\mathrm{e}$ & $\mathrm{k}_{\mathrm{d} 4}$ & & (R4) \\
\hline $\mathrm{O}^{*}+\mathrm{H}_{2} \mathrm{O} \rightarrow \mathrm{OH}^{*}+\mathrm{OH}^{-}$ & $\mathrm{k}_{\mathrm{e} 1}$ & $2.2 \times 10^{-10}$ & (R5) \\
\hline $\mathrm{NO}+\mathrm{O}^{\cdot}+\mathrm{M} \rightarrow \mathrm{NO}_{2}+\mathrm{M}$ & $\mathrm{k}_{1}$ & $3.0 \times 10^{-11}(\mathrm{~T} / 300)^{0.3}$ & (R6) \\
\hline $\mathrm{SO}_{2}+\mathrm{OH}+\mathrm{M} \rightarrow \mathrm{HSO}_{3+} \mathrm{M}$ & $\mathrm{k}_{5}$ & $1.3 \times 10^{-12}(\mathrm{~T} / 300)^{-0.7}$ & (R10) \\
\hline $\mathrm{HSO}_{3}+\mathrm{O}_{2} \rightarrow \mathrm{SO}_{3}+\mathrm{HO}_{2}$ & $\mathrm{k}_{6}$ & $1.1 \times 10^{-13} \exp (-1200 / \mathrm{T})$ & (R11) \\
\hline $\mathrm{SO}_{3}+\mathrm{H}_{2} \mathrm{O} \rightarrow \mathrm{H}_{2} \mathrm{SO}_{4}$ & $\mathrm{k}_{7}$ & $3.9 \times 10^{-41} \exp (6830 / \mathrm{T})\left[\mathrm{H}_{2} \mathrm{O}\right]^{2}$ & (R12) \\
\hline $\mathrm{N}^{\prime}+\mathrm{OH}^{\prime} \rightarrow \mathrm{NO}^{\circ}+\mathrm{H}^{\circ}$ & $\mathrm{k}_{8}$ & $3.8 \times 10^{-11} \exp (85 / \mathrm{T})$ & (R13) \\
\hline $\mathrm{N}^{-}+\mathrm{NO} \rightarrow \mathrm{N}_{2}+\mathrm{O}^{\cdot}$ & $\mathrm{k}_{9}$ & $3.1 \times 10^{-11}$ & (R14) \\
\hline $\mathrm{N}^{\prime}+\mathrm{NO}_{2} \rightarrow \mathrm{N}_{2} \mathrm{O}+\mathrm{O}^{\circ}$ & $\mathrm{k}_{10}$ & $3.0 \times 10^{-12}$ & (R15) \\
\hline
\end{tabular}

Radical formations and radical + molecule reactions are very fast and highly dependent on the reaction rates. While reaction rate of electron impact depends on the electron energy and cross-section of impact, reaction rate of radical + molecules depend on the chemistry and temperature of the gas. The reactions given Table 1 play dominant roles in the formation of radicals and conversion of NOx and SOx into $\mathrm{H}_{2} \mathrm{SO}_{4}$ and $\mathrm{HNO}_{3}$.

Table 1 also shows associated reaction rate constants of the radical + gas reactions and reactions rate constants of the electron impact reactions $\left(\mathrm{k}_{\mathrm{d} 1}, \mathrm{k}_{\mathrm{d} 2}, \mathrm{k}_{\mathrm{d} 3}\right.$ and $\left.\mathrm{k}_{\mathrm{d} 4}\right)$ are calculated using the following equations (1) and (2);

$k d_{j}=\sqrt{\frac{2 q}{m_{e}}} \int_{0}^{\infty} \varepsilon \sigma_{j}(\varepsilon) f(\varepsilon) d \varepsilon$

where, $q$ - charge of the electron, e; $m_{e}$ - mass of the electron; $\varepsilon$ - electron energy $(\mathrm{V}), \sigma_{\mathrm{j}}$ collision cross section area $\left(\mathrm{m}^{2}\right)$ of $\mathrm{j}^{\text {th }}$ electron impact reaction; $\mathrm{f}(\varepsilon)$ - electron energy distribution function (EEDF) and $\mathrm{j} \epsilon(1,2,3,4)$.

In many cases, either the Maxwellian EEDF (MEEDF) or the Druyvestein EEDF have been used; for low mean electron energy $(<16.6 \mathrm{eV})$ there is no significant difference between these two distributions [31]. In this work, the Maxwellian EEDF is used since the mean electron energy in the plasma is expected to be low [9]. The Maxwellian EEDF can be expressed as:

$\mathrm{f}(\varepsilon)=\gamma^{-1.5} \mathrm{~b}_{1} \mathrm{e}^{\left(-\frac{\varepsilon \mathrm{b}_{2}}{\gamma}\right)}$

where $\quad \gamma$-mean electron energy of a single electron

$b_{1}=G(2.5)^{1.5} G(1.5)^{-2.5}$

$b_{2}=G(1.25) G(0.75)^{-1}$

and $G(x)$ is known as Gamma function and given by the following integral;

$\mathrm{G}(\mathrm{x})=\int_{0}^{\infty} \mathrm{e}^{-\mathrm{v}} \mathrm{v}^{\mathrm{x}-1} \mathrm{dv}$

where $\mathrm{v}$ is a dummy variable and used to evaluate the integral.

The calculated rate constants of electron impacts are shown in Fig 1. The cross-section data for the electron impact reactions (1) to (4) was obtained from the published literature [32-37]. As can be seen, there is a significant variation in the way electron impact rate constant varies against the mean 
electron energy of the plasma. This variation plays a vital role in the NOx and SOx conversion.

The differential equations of concentration change of each species involved in the reactions (Table 1) is derived using mass balanced equations and solved by using MATLAB solver ode15s. Set of typical results from the computer simulations are shown in Fig. 2 for $1 \mathrm{eV}$ mean electron energy. These results were obtained for a typical exhaust composition of a two stroke marine diesel engine; $\mathrm{O}_{2}$ (13.0\%), $\mathrm{N}_{2}$ (75.8\%), $\mathrm{CO}_{2}$ (5.2\%), $\mathrm{H}_{2} \mathrm{O}$ (5.35\%), $\mathrm{NO}$ (75 vppm), $\mathrm{NO}_{2}(1500 \mathrm{vppm}), \mathrm{SOx}(600 \mathrm{vppm})$ and $\mathrm{CO}$ (60 ppm) and $\mathrm{HC}(180 \mathrm{ppm})$ and mean electron energy of plasma $1 \mathrm{eV}$.

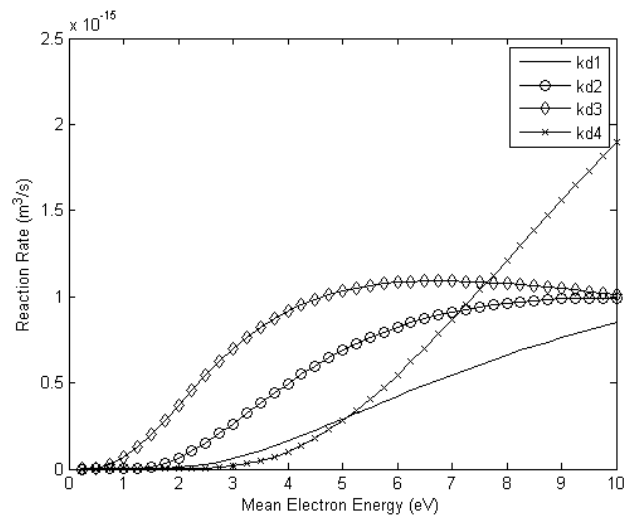

Fig.1: Electron impact reaction rates against mean electron energy of
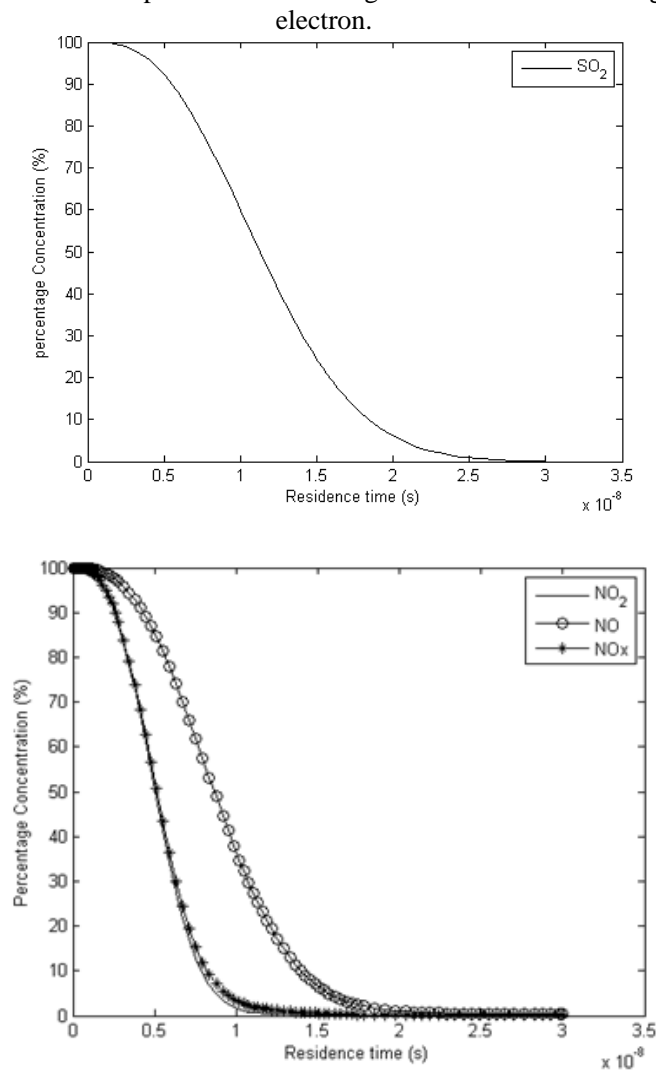

Fig. 2: Abatement of $\mathrm{SO}_{2}$ (top) and NOx (bottom) with NTP: mean electron

$$
\begin{aligned}
& \text { Fig. 2: Abatement of } \mathrm{SO}_{2} \text { (top) and } \mathrm{NOx} \text { (bottom } 1 \mathrm{eV} . \\
& \text { energy is } 1 \mathrm{e}
\end{aligned}
$$

The microwave cavity to produce the NTP for a given flow rate was designed using COMSOL multi-physics software. The full details of the design can be found in [20]. The major criterion in the design process was to produce high electric field intensity within the cavity where exhaust gas is exposed and plasma is produced. The final design of the MW based NTPR (reactor and waveguide) is shown in the Fig. 3. As it is shown, gas inlet and outlet ports are conical in shape in order to avoid the MW leakage through. The diameter of a circular waveguide should be less than $70 \mathrm{~mm}$ to avoid any MW leakage as calculated from the following equation:

$$
d>3.6824 c /\left(2 \pi f_{c}\right)
$$

where $f_{c}$ is the upper cut-off frequency of MW and $c$ is the speed of light.

The diesel exhaust gas passes through a quartz tube with $20 \mathrm{~cm}$ outer diameter, $50 \mathrm{~cm}$ length and $10 \mathrm{~mm}$ thick to accommodate flow rates up to $200 \mathrm{l} / \mathrm{s}$, withstand vibrations and non-thermal plasma as well as the marine exhaust gas temperatures. The major reason for the choice of quartz tube is that it is transparent to $\mathrm{MW}$ and prevents the exhaust gas from leaking into waveguide and magnetrons, thereby avoiding contamination and potential damage of the magnetrons. Microwave energy is injected into the cavity through a number of slots from two parallel waveguides placed each on one a lateral side of the reactor (Fig. 3). The wave guides used are of WR340 with the cross section of $86.36 \mathrm{~mm}$ by $43.18 \mathrm{~mm}$ to accommodate frequency up to $3.36 \mathrm{GHz}$ for $\mathrm{TE}_{10}$ mode. There are six slots on each waveguide and they are slanted at $19.9^{\circ}$ angle to horizontal and curved at the both ends (semicircles with radius of $8 \mathrm{~mm}$ ). The reason for these curves is to avoid any electric discharges at the sharp corners. The slots are separated by the halfwavelength of the waveguide $\lambda_{\mathrm{g}}$, in order to have maximum MW energy injection through the slots. The wavelength of the waveguide is calculated from the following equation:

$$
\lambda_{\mathrm{g}}=\frac{\lambda_{\mathrm{o}}}{\sqrt{1-\left(\frac{\lambda_{\mathrm{o}}}{2 \mathrm{a}}\right)^{2}}}
$$

where $\lambda_{0}$ is the wavelength of the microwave $(=122 \mathrm{~mm})$, a is the longest length of the rectangular cross section. In the current set-up, $\mathrm{a}=96 \mathrm{~mm}$ and the resulting $\lambda \mathrm{g}$ is $158.8 \mathrm{~mm}$. 


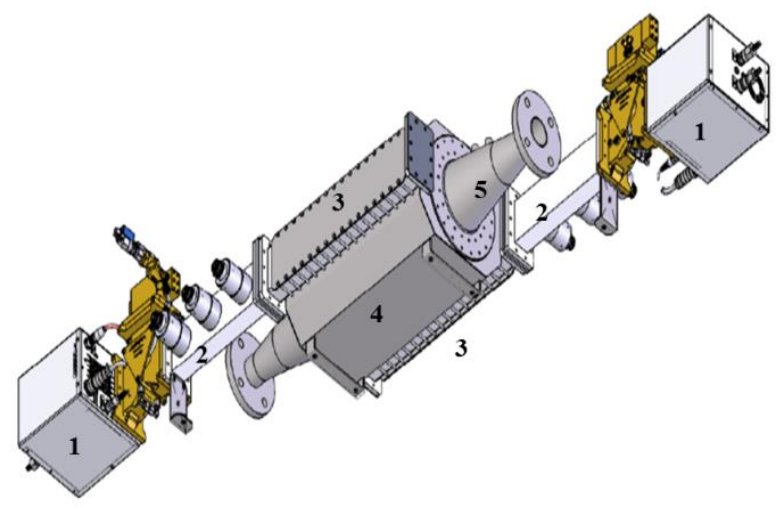

(a)

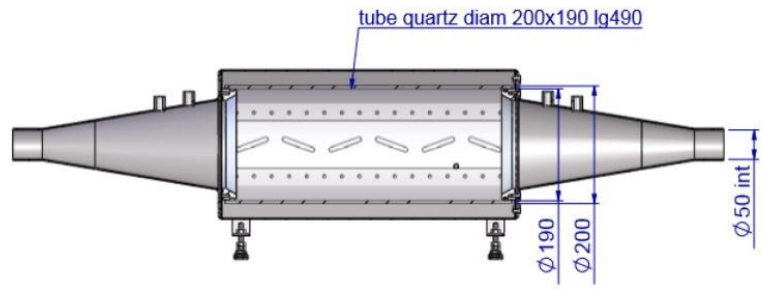

(b)

Fig. 3. Brunel Pilot scale NTPR and $2 \times 2 \mathrm{~kW}$ power MW set-up. (a) 3D Schematic: 1- microwave generators (magnetron, Isolator, water cooling and MW power measurement); 2 -stub tuners; 3 - waveguides; 4 - multi-mode cavity; 5 - gas inlet/outlet. (b) side view of the NTPR, showing the reactor dimensions and slot arrangement.

The MW system was manufactured by Sairem from France and comprises of a $2 \mathrm{~kW}$ power supply for each $2.45 \mathrm{GHz}$ magnetron, manual stub tuners to regulate the amount of reflected power and parallel MW launching waveguides designed to create regions of maximum MW energy concentration within the NTPR.

A computer Finite Element Method (FEM) model was developed for the Brunel pilot scale NTPR using COMSOL Multi-Physics software. The main objective of the simulation is to understand the electric field distribution within the multi-mode cavity, especially in the quartz tube area. The following equation was solved in frequency domain by COMSOL to determine the electric field distribution in the waveguide and NTPR:

$\nabla \times \mu_{\mathrm{r}}^{-1}(\nabla \times \mathrm{E})-\mathrm{K}_{0}^{2}\left(\epsilon_{\mathrm{r}}-\frac{\mathrm{j} \sigma}{\omega \epsilon_{0}}\right) \mathrm{E}=0$

where $\mu_{\mathrm{r}}$ - permeability of the medium, $\varepsilon_{0}$ - permittivity of medium, E - electric field vector, $\sigma$ - density of medium, and $\mathrm{K}_{0}$ - wave number. The walls of the wave guide and NTPR are assumed to be perfect conductors and the following boundary condition was applied:

$\mathrm{n} \times \mathrm{E}=0$

where $\mathrm{n}$ - normal vector to the walls.
A number of simplification steps were taken to increase the simulation speed without losing any significant accuracy in the results:

- Magnetrons, water cooling, isolator, 3-stub tuner were not included in the model as they do not influence the electric field pattern in any way.

- Multimode cavity, inlet/outlet ports and waveguide were considered to be perfect conductor, so energy is not lost at these boundaries.

- All MW power from the magnetrons was going into the waveguide.

The results obtained from the simulation are shown in Fig. 4.

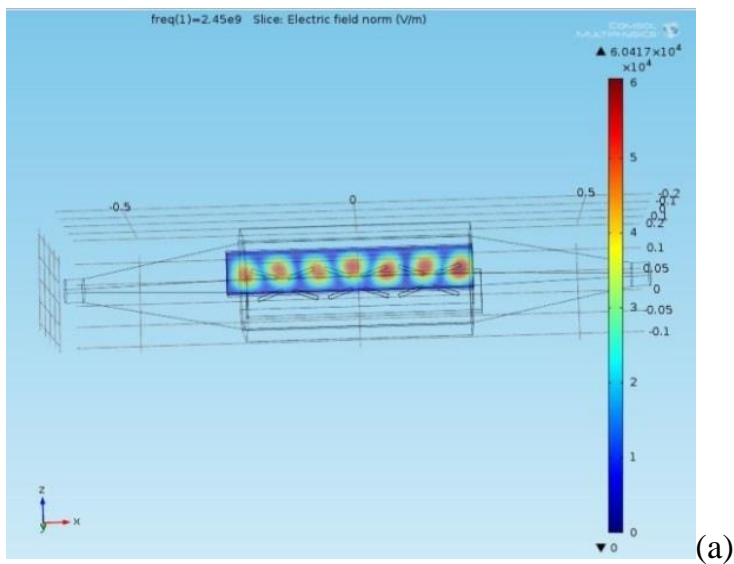

(b)

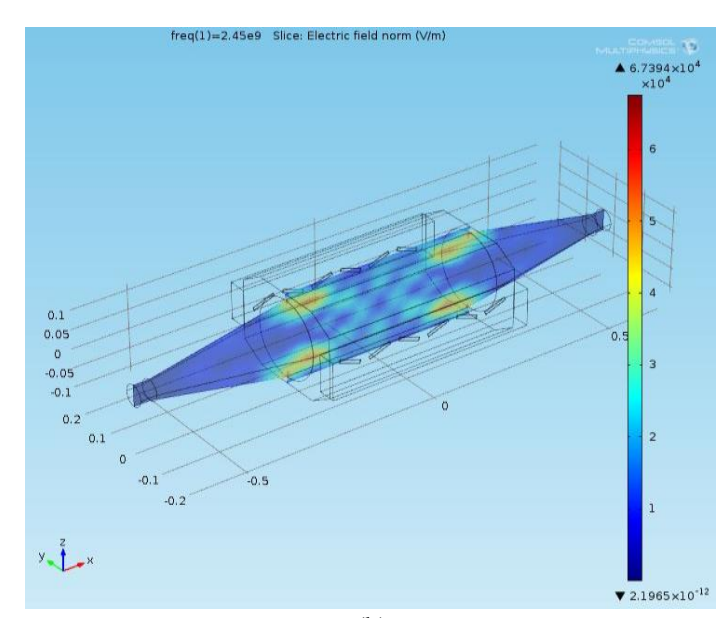

(a) 


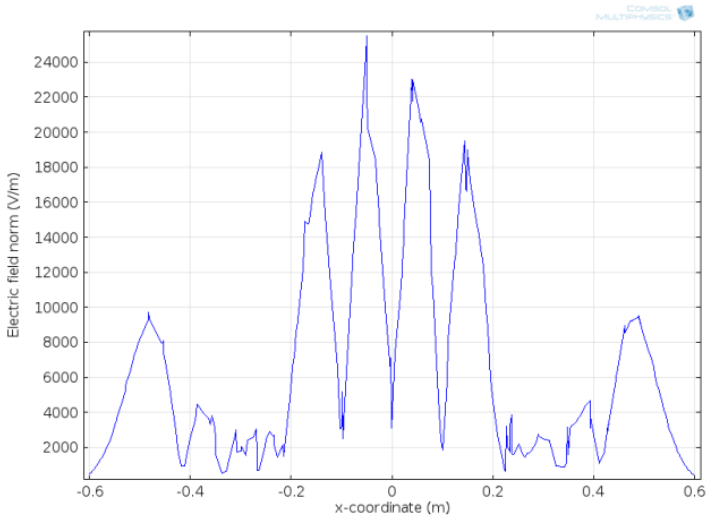

(c)

Fig. 4: MW field modeling: a) Electric field in waveguide (z-x plane). b) Electric field in NTPR ( $\mathrm{x}-\mathrm{z}$ plane). c) Electric field (Line scan across middle of the NTPR)

Standing wave pattern of Electric field in waveguide is shown in Fig. 4(a), where it displays the slot location in relation to the high intensity field. It was found that when the centers of the slots are located at the nodes of the standing wave pattern a stronger electric field is obtained in the cavity. Fig. 4(b) shows the electric filed pattern in the $x-y$ plane of the cavity. The plots clearly show that there is no electric field in the gas inlet and outlet cones of the NTPR, thus no MW leaks in the system. Fig. 4(c) shows a line scan in the middle of the NTPR showing that the highest electric field strength is within the quartz tube middle section.

\section{EXPERIMENTAL SET-UP}

Fig. 5(a) shows the MW plasma experimental pilot scale setup used in Brunel University laboratory. This set-up includes multi-mode microwave cavity, diesel gen-set, Testo350 gas measurement systems (x2), $30 \mathrm{kV}$ high voltage supply, gas flow rate meter and data logging system. Two 2 $\mathrm{kW}$ microwave generators operating at $2.45 \mathrm{GHz}$ were used to supply required microwave energy into the microwave cavity through two slotted waveguides as used in the previous section. The exhaust gas was generated from a $2 \mathrm{~kW}$ diesel generator with gas flow rate up to $20 \mathrm{l} / \mathrm{s}$ and high concentration of $\mathrm{NOx}\left(\mathrm{NO}\right.$ and $\left.\mathrm{NO}_{2}\right)$ up to $750 \mathrm{ppm}$ while $\mathrm{O}_{2}$ concentration was around $5.5 \%$ in volume. Gas concentration of NOx was measured at the inlet \& outlet of the NTPR with two portable gas analyzers (testo 350) manufactured by testo AG, Germany.

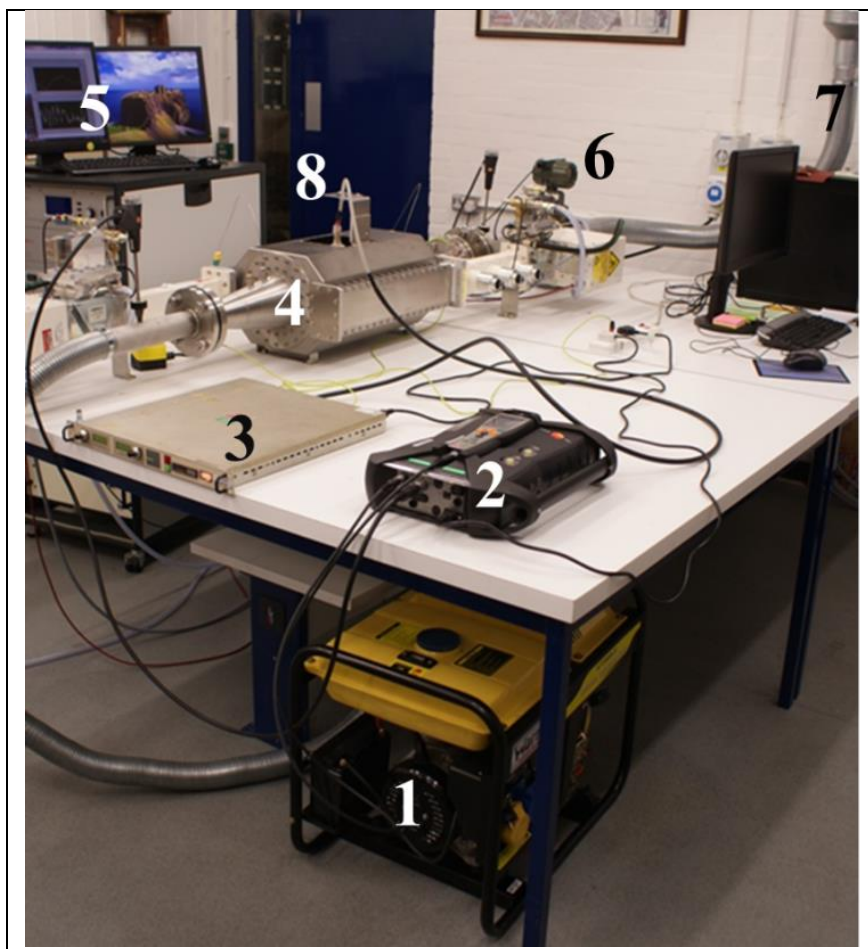

(a)

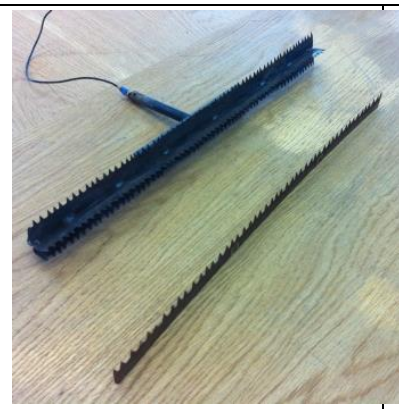

(b)

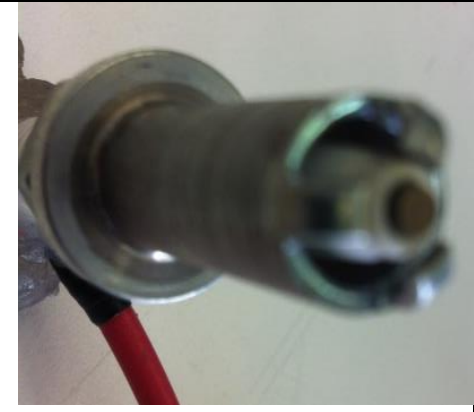

(c)
Fig.5: MW NTPR set up (a) : 1- $2 \mathrm{~kW}$ gen-set; 2 - Testo gas analyzer at inlet/outlet of NTPR; 3 - Spelman $30 \mathrm{kV} \mathrm{DC} \mathrm{power} \mathrm{supply;} 4$ - MW based NTPR; 5 - MW control and data acquisition and recording; 6 - Flow meter; 7 - Gas extraction; 8 - Spark plug and (b) saw tooth (c) spark plug.

Temperature at inlet/outlet was also measured by testo 350 in addition to the dedicated temperature sensors. MW outlet/reflected power, and current gas flow rate, gas/plasma temperature were recorded and stored through a dedicated data acquisition system - (a bespoke programmed LabView DAQ system). Grounded meshes were placed at the inlet and outlet of the NTPR gas path to avoid any plasma leakages. A number of techniques were adopted to ignite MW plasma: AC/DC corona discharges, passive electrodes and high frequency AC spark plugs.

Fig. 6 shows a typical NOx concentration from the exhaust of the diesel gen-set at high load for 30 minutes. The diesel exhaust inlet temperature was very stable $195{ }^{\circ} \mathrm{C}$, while the outlet varied between $120-170{ }^{\circ} \mathrm{C}$ depending on the $\mathrm{MW}$ energy applied (power and duration) and plasma. Fig. 7 shows a combination of MW and DC Corona set-up. A DC 
corona electrode system is placed within the quartz tube of the NTPR.

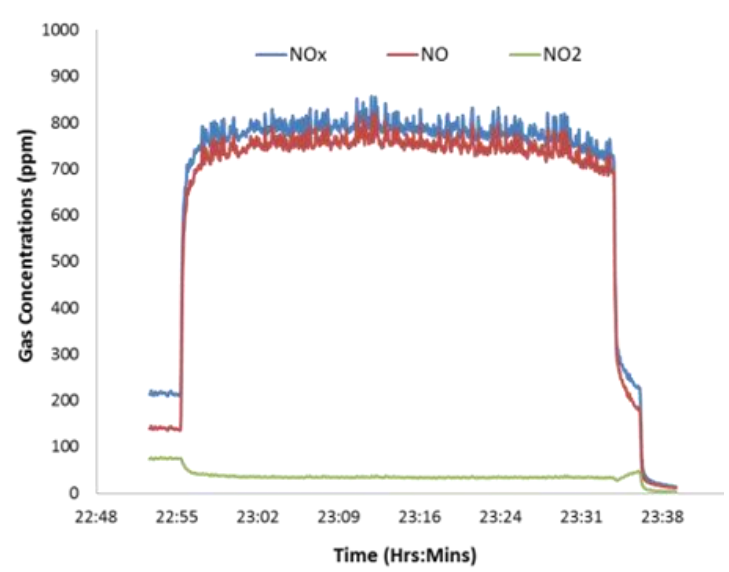

Fig. 6: Concentration of NOx and $\mathrm{SO} 2$ from the exhaust of the $2 \mathrm{~kW}$ gen-set at high load

Following techniques were adapted to initialize the plasma; AC/DC corona, DC corona, spark-plugs, passive electrodes (needle electrode, saw-tooth electrode and cross-saw-tooth electrodes). Though these passive electrodes (saw-tooth and needle) have shown excellent results in ignition, but igniting and maintaining plasma is still a big challenge. The saw tooth and spark-plugs (commercially available car spark-plug) used are shown in Fig. 5(b) and Fig. 5(c).

\section{EXPERIMENTAL RESULTS AND DISCUSSION}

The pilot scale reactor has a fully controlled MW system that can be precisely controlled from the stub tuners to transfer maximum MW energy into the cavity. When enough power is supplied to the sharp tips of the passive electrode, the electrode will ignite the plasma as can be seen in Fig. 7. This figure shows two types of MW plasma that occurred within the NTPR reactor as the diesel exhaust passes through. The top ones are yellow-orange in color and the bottom ones are purple-blue. The yellow-orange plasma is capable of removing the soot, unburned fuel, lubricating oil and other gaseous components of the diesel exhaust including removal NOx and SOx.
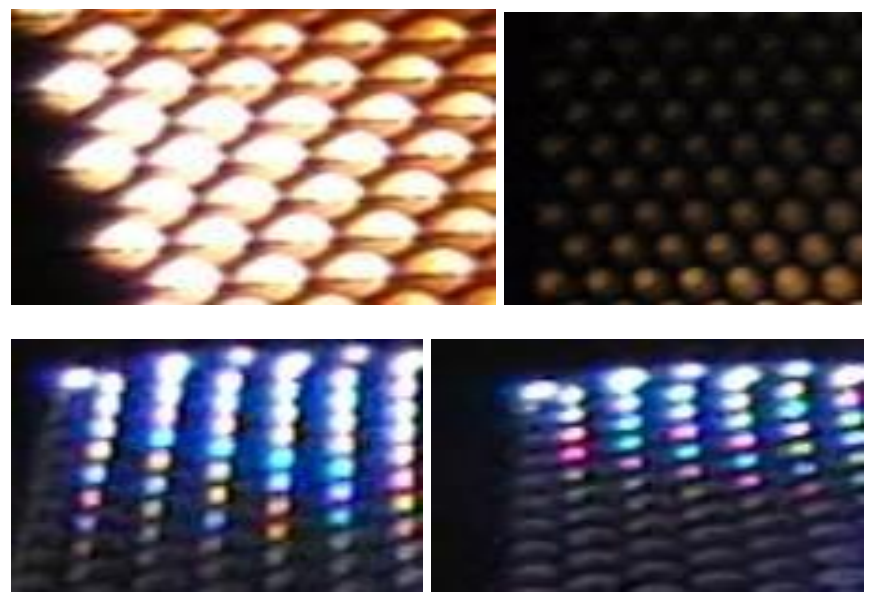

Fig. 7: Microwave plasma formed by the saw tooth

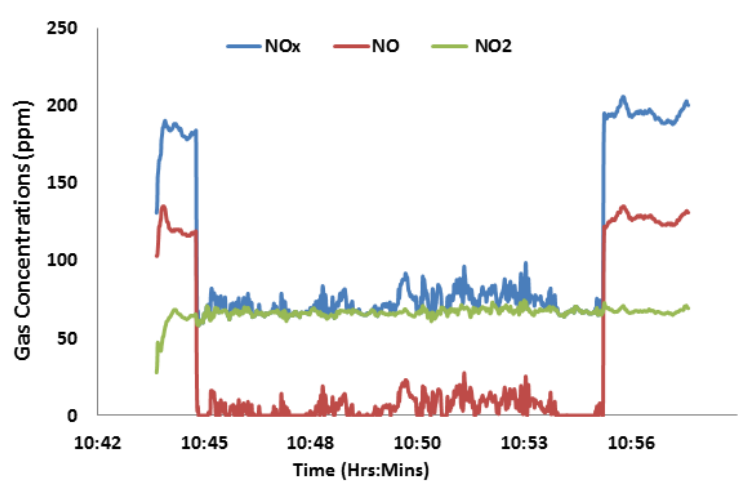

Fig. 8: NO reduction with MW purple plasma.

The results presented in Fig. 8 was obtained with the following input conditions: $1.8 \mathrm{~kW}$ total $\mathrm{MW}$ power, low sulphur diesel fuel in the $2 \mathrm{~kW}$ gen-set running at low load $(\approx 180 \mathrm{ppm}$ NOx$)$, gas inlet/outlet temperatures were $100{ }^{\circ} \mathrm{C}$ and $70{ }^{\circ} \mathrm{C}$. One magnetron was set-up at $1 \mathrm{~kW}$ power and had $0.2 \mathrm{~kW}$ reflected power, while the other magnetron was setup at $0.6 \mathrm{~kW}$ power with a $0.1 \mathrm{~kW}$ reflected power. The reflected power varied slightly during the period of experiment and was controlled through the stub tuners on both magnetrons. A single saw tooth blade passive electrode $500 \mathrm{~mm}$ length was positioned in the center of the NTPR. As soon as the MW purple plasma ignited and was kept stable in the same position, NO drops to very low value $(0-20 \mathrm{ppm})$. $\mathrm{NO}_{2}$ was not affected as being more stable gas and it requires more energy to break down into radicals than that of NO. 


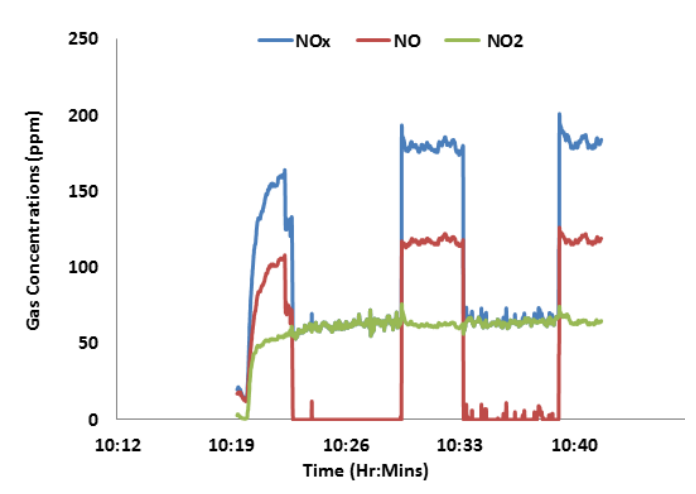

Fig. 9: NO reduction in two consecutive stable yellow MW plasmas

Fig. 9 replicates the NO reduction results with same exhaust condition and two purple plasmas were produced, each kept on for duration of 5 minutes. In both cases NO drops to $0 \mathrm{ppm}, \mathrm{NO}_{2}$ is not affected.

Fig 10(a) shows the NTPR output gas NOx concentration for the exhaust from the gen-set at low load with low sulphur fuel. A cross saw tooth blade passive electrode was positioned in the center of the quartz tube; cross saw tooth increasing the area of sharp points and thus increasing the chance to ignite the plasma. The exhaust gas temperature at the inlet of the NTPR was $105^{\circ} \mathrm{C}$ and outlet was $40{ }^{\circ} \mathrm{C}$ when no plasma was present. When $\mathrm{MW}$ plasma was ignited, the temperature at outlet was increased by $60{ }^{\circ} \mathrm{C}$ to $106{ }^{\circ} \mathrm{C}$. The plasma was created when microwave power supplied was about $1 \mathrm{~kW}$ (The MW forward power was $1 \mathrm{~kW}$ and $0.6 \mathrm{~kW}$ and reflected power $0.3 \mathrm{~kW}$ ).

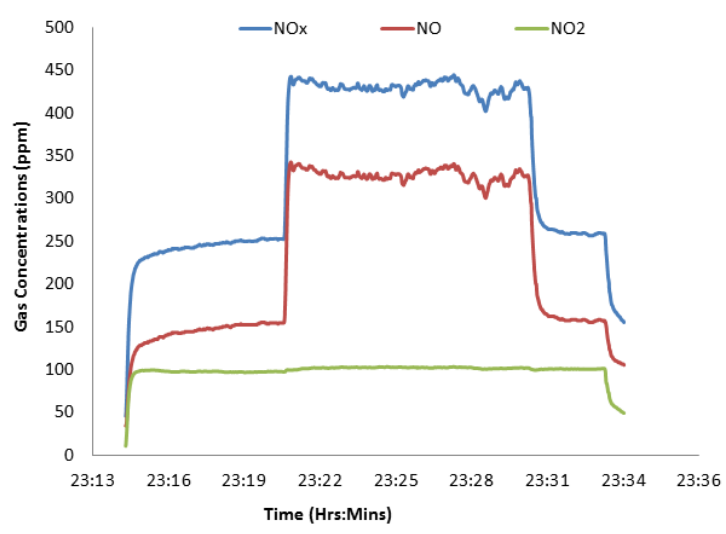

(a)

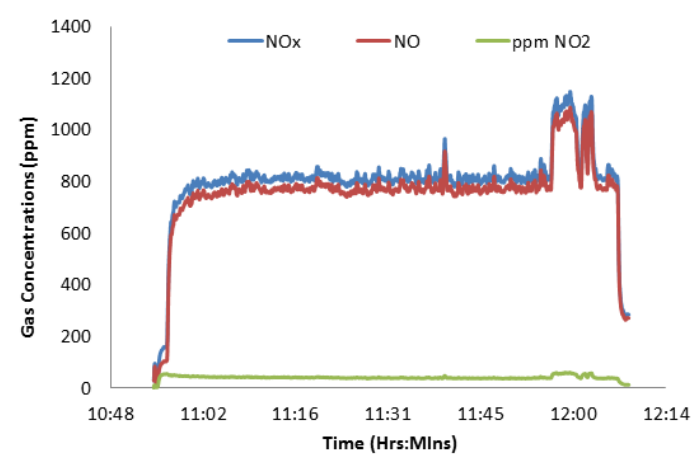

(b)

Fig. 10: $\mathrm{NO}$ and $\mathrm{NO}_{2}$ increase in the presence of a purple plasma.

The gas flow rate was $201 / \mathrm{s}$. On this occasion, purple plasma was generated which was maintained for 10 minutes, however, the concentration of $\mathrm{NO}$ was increased. The purple plasma was due to the presence of $\mathrm{N}_{2}$ (and hence $\mathrm{N}$ radicals) which is capable of reducing NOx in to $\mathrm{N}_{2}$ if there is no $\mathrm{O}_{2}$ in the exhaust gas [17], which was not the case here; in contrast it can adversely affect the exhaust by producing more NO in $\mathrm{N}_{2}-\mathrm{O}_{2}$ rich environment through following reaction.

$\mathrm{N} \cdot+\mathrm{O} \rightarrow \mathrm{NO}_{2}+\mathrm{O} \cdot$

It was also noticed that the soot deposited on the walls of the quartz tube was completely removed by purple plasma, which is an interesting results that needs further investigation.

Fig. 10 (b) shows the NTPR output gas levels when the genset was on high load and producing 840 ppm NOx. The same cross tooth passive electrodes were used, although many of its sharp points were consumed in the previous reaction. This experiment lasted one hour in which we gradually increased the MW power on both magnetrons. NTPR gas inlet temperature was $195{ }^{\circ} \mathrm{C}$ while at the output $140{ }^{\circ} \mathrm{C}$, flow rate 201/s. There was no effect on the gas composition when using the magnetron at low power but when MW power setting was one at $1 \mathrm{~kW}$ power and the other at $1 \mathrm{~kW}$ with reflected power of $0.1 \mathrm{~kW}$, purple plasma was ignited for a short duration. Both NO increased by $25 \%$ as a result for the same reason mentioned above.

The generation of yellow plasma without purple plasma is an interesting but challenging phenomena that also needs further investigation.

\section{CONCLUSIONS AND FURTHER WORK}

A pilot scale non-thermal plasma reactor (NTPR) based on microwave plasma was modeled, built and tested. The NTPR can sustain significant temperature variations and high flow rates $\approx 200 \mathrm{l} / \mathrm{s}$. The NTPR was built on a mobile platform so that it can be easily transported to any location for test with exhaust from different types of engines. 
Computer simulation of NTP kinetics was performed and results clearly showed that in theory, if right plasma is ignited (thus mean electron energy is below $3.2 \mathrm{eV}$ ), then complete removal of $\mathrm{NOx}$ and $\mathrm{SO}_{2}$ is possible. Some of our simulation results were reported in our previous publications.

The NTPR was tested in various operation conditions (genset low/high load and plasma ignition power levels) and it was found that type of plasmas (yellow and purple) can be ignited within the MW filed depending on the MW electric filed strength. While yellow plasma removed NO completely, purple plasma performed adversely by increasing NIO concentration. A future work is recommended from this study to investigate how stable plasma can be created and controlled in a large volume for pilot-scale NOx removal.

\section{ACKNOWLEDGEMENTS}

The work was supported by the European Commission under DEECON FP7 European Project, "Innovative AfterTreatment System for Marine Diesel Engine Emission Control", contract No. 284745. We are also grateful to Dr Marilena Radoiu, R\&D Director of Sairem for her professionalism and knowledge exchange regarding the Microwave system. Big thanks to Dr Jeremy Ahern for his continuous assistance and support with experiments and logistics.

\section{References}

[1] V. Jurić and D. Županović, "Ecological Impacts of Diesel Engine Emissions," PROMET-Traffic\&Transportation, vol. 24, pp. 151-160, 2012.

[2] L. Boone, "Reducing Air Pollution from Marine Vessels to Mitigate Arctic Warming: Is it Time to Target Black Carbon," CCLR, pp. 13, 2012.

[3] Ø Endresen, S. Dalsøren, M. Eide, I. Isaksen and E. Sørgård, "The environmental impacts of increased international maritime shipping-Past trends and future perspectives," in Proceedings of the Global Forum on Transport and Environment in a Globalising World, Guadalajara, Mexico, November, 2008, pp. 10-12.

[4] W. A. Majewski and M. K. Khair, Diesel Emissions and their Control. Society of Automotive Engineers, 2006.
[5]. Risk Assessment for Toxic Air Pollutants: A Citizen's Guide. (March 1991) Available: http://www3.epa.gov/airtoxics/3 90 024.html.

[6] V. Eyring, I. S. Isaksen, T. Berntsen, W. J. Collins, J. J. Corbett, O. Endresen, R. G. Grainger, J. Moldanova, H. Schlager and D. S. Stevenson, "Transport impacts on atmosphere and climate: Shipping," Atmos. Environ., vol. 44, pp. 4735-4771, 2010.

[7] D. Gregory and N. Confuorto, A Practical Guide to Exhaust Gas Cleaning Systems for the Maritime Industry. London: EGCSA, 2012.

[8] T. Kuwahara, T. Kuroki, M. Okubo, K. Yoshida, K. Hanamoto and K. Sato, "Pilot-scale experiment of total marine diesel emission control using ozone injection and nonthermal plasma reduction," in Industry Applications Society Annual Meeting, 2013 IEEE, 2013, pp. 1-11.

[9] R. McAdams, "Prospects for non-thermal atmospheric plasmas for pollution abatement," J. Phys. D, vol. 34, pp. 2810, 2001.

[10] J. Brandt, L. Frohn, J. Christensen, M. Andersen, O. Hertel, C. Geels, A. B. Hansen, K. Hansen, G. Hedegaard and C. Skjøth, "Assessment of health-cost externalities of air pollution at the national level using the EVA model system," Collection of Extended Abstracts, pp. 91, 2010.

[11] C. Andersson, R. Bergström and C. Johansson, "Population exposure and mortality due to regional background PM in Europe - Long-term simulations of source region and shipping contributions," Atmos. Environ., vol. 43, pp. 3614-3620, 7, 2009.

[12] L. Benbrahim-Tallaa, R. A. Baan, Y. Grosse, B. LaubySecretan, F. El Ghissassi, V. Bouvard, N. Guha, D. Loomis, K. Straif and International Agency for Research on Cancer Monograph Working Group, "Carcinogenicity of dieselengine and gasoline-engine exhausts and some nitroarenes," Lancet Oncol., vol. 13, pp. 663-664, Jul, 2012.

[13] "Shipping 2020," DNV, Oslo, 2012.

[14] Wärtsilä Open Loop Scrubber System. Available: http://www.wartsila.com/products/marine-oil-gas/exhaustgas-cleaning/sox-abatement/wartsila-open-loop-scrubbersystem.

[15] R. Brandenburg, A. G. Chmielewski, A. Pawelec, E. Stamate, H. Barankova, H. Grosch, I. Jõgi, J. Mizeraczyk, L. Bardos and M. Hołub, Plasma-Based Depollution of Exhausts: Principles, State of the Art and Future Prospects. INTECH Open Access Publisher, 2011. 
[16] P. Talebizadeh, M. Babaie, R. Brown, H. Rahimzadeh, Z. Ristovski and M. Arai, "The role of non-thermal plasma technique in NO x treatment: A review," Renewable and Sustainable Energy Reviews, vol. 40, pp. 886-901, 2014.

[17] T. Kuwahara, K. Yoshida, K. Hanamoto, K. Sato, T. Kuroki and M. Okubo, "A Pilot-Scale Experiment for Total Marine Diesel Emission Control Using Ozone Injection and Nonthermal Plasma Reduction," Industry Applications, IEEE Transactions On, vol. 51, pp. 1168-1178, 2015.

[18] A. Chmielewski, "Application of ionizing radiation in environmental protection," Radiation Treatment of Gaseous and Liquid Effluents for Contaminant Removal, pp. 11, 2005.

[19] I. Calinescu, D. Ighigeanu, D. Martin and A. Bulearca, "Electron beam technologies for reducing SO2 and NOx emissions from thermal power plants," in WEC Regional Energy Forum-Foren, 2008, pp. 15-19.

[20] N. Manivannan, W. Balachandran, R. Beleca. and M. Abbod, "Microwave Plasma System Design and Modelling for Marine Diesel Exhaust Gas Abatement of NOx and SOx," International Journal of Environmental Science and Development, vol. 6, pp. 151, Feb 2015., 2015.

[21] J. L. Hueso, A. R. González-Elipe, J. Cotrino and A. Caballero, "Removal of $\mathrm{NO}$ in NO/N2, NO/N2/O2, $\mathrm{NO} / \mathrm{CH} 4 / \mathrm{N} 2$, and NO/CH4/O2/N2 systems by flowing microwave discharges," The Journal of Physical Chemistry A, vol. 111, pp. 1057-1065, 2007.

[22] A. M. Harling, D. J. Glover, J. C. Whitehead and K. Zhang, "Novel method for enhancing the destruction of environmental pollutants by the combination of multiple plasma discharges," Environ. Sci. Technol., vol. 42, pp. 45464550, 2008.

[23] M. Abbod, R. Beleca, D. Peirce, L. Gannipa, N. Manivannan and W. Balachandran, "Power controlled microwave reactor for the removal of NOx and SOx from the exhaust of marine diesel engine," in Proc. 2014 Transport Research Arena Conf, 2014, .

[24] A. Jaworek, W. Balachandran, A. Krupa, J. Kulon and M. Lackowski, "Wet electroscrubbers for state of the art gas cleaning," Environ. Sci. Technol., vol. 40, pp. 6197-6207, 2006.

[25] A. Jaworek, M. Szudyga, A. Krupa, T. Czech, A. T. Sobczyk, A. Marchewicz, T. Antes, W. Balachandran, R. Beleca and F. Di Natale, "Technical issues of PM removal from ship diesel engine exhausts," in Transport Research Arena (TRA) 5th Conference: Transport Solutions from Research to Deployment, 2014, .
[26] J. Chae, "Non-thermal plasma for diesel exhaust treatment," J. Electrostatics, vol. 57, pp. 251-262, 2003.

[27] J. Kjølholt, S. Aakre, C. Jürgensen and J. Lauridsen, "Assessment of possible impacts of scrubber water discharges on the marine environment," Kobenhavn: Environmental Protection Agency, Danish Ministry of Environment, 2012.

[28] R. Atkinson, D. L. Baulch, R. A. Cox, R. F. Hampson, J. A. Kerr (Chairman) and J. Troe. Evaluated kinetic and photochemical data for atmospheric chemistry: Supplement III. IUPAC subcommittee on gas kinetic data evaluation for atmospheric chemistry. Journal of Physical and Chemical Reference Data 18(2), pp. 881-1097. 1989.

[29] R. Atkinson, D. L. Baulch, R. A. Cox, J. N. Crowley, R. F. Hampson, R. G. Hynes, M. E. Jenkin, M. J. Rossi and J. Troe, "Evaluated kinetic and photochemical data for atmospheric chemistry: Volume I - gas phase reactions of O\$_x $\$, H O \$$ X\$, NO\$_x\$ and SO\$_x\$ species," Atmospheric Chemistry and Physics, vol. 4, pp. 1461-1738, 2004.

[30] N. Manivannan, W. Balachanran, R. Beleca and M. Abbod, "Non-Thermal Plasma Technology for the Abatement of NOx and SOx from the Exhaust of Marine Diesel Engine," Journal of Clean Energy Technologies, vol. 2, pp. 233-236, 2014.

[31] A. Boichenko, G. Evtushenko, S. Yakovlenko and O. Zhdaneev, "Analysis of the electron energy distribution function in a copper-vapor laser with modified kinetics," LASER PHYSICS-LAWRENCE-, vol. 14, pp. 922-929, 2004.

[32] P. Cosby, "Electron-impact dissociation of oxygen," $J$. Chem. Phys., vol. 98, pp. 9560-9569, 1993.

[33] H. Straub, P. Renault, B. Lindsay, K. Smith and R. Stebbings, "Absolute partial cross sections for electronimpact ionization of $\mathrm{H} 2, \mathrm{~N} 2$, and $\mathrm{O} 2$ from threshold to 1000 eV," Physical Review A, vol. 54, pp. 2146, 1996.

[34] R. Stebbings and B. Lindsay, "Comment on the accuracy of absolute electron-impact ionization cross sections for molecules," J. Chem. Phys., vol. 114, pp. 4741-4743, 2001.

[35] A. Phelps and L. Pitchford, "Anisotropic scattering of electrons by $\mathrm{N} 2$ and its effect on electron transport," Physical Review A, vol. 31, pp. 2932, 1985.

[36] S. Lawton and A. Phelps, "Excitation of the b $1 \Sigma \mathrm{g}$ state of $\mathrm{O} 2$ by low energy electrons," J. Chem. Phys., vol. 69, pp. 1055-1068, 1978. 
[37] P. Cosby, "Electron-impact dissociation of nitrogen," $J$. Chem. Phys., vol. 98, pp. 9544-9553, 1993. 